\title{
Intracisternal delivery of PEG-coated gold nanoparticles results in high brain penetrance and long-lasting stability
}

\author{
Antonello Spinelli ${ }^{1 \dagger}$, Maria Girelli2 ${ }^{2 \dagger}$, Daniela Arosio ${ }^{3}$, Laura Polito ${ }^{3}$, Paola Podini ${ }^{4}$, Gianvito Martino ${ }^{2}$, \\ Pierfausto Seneci ${ }^{5}$, Luca Muzio ${ }^{2^{*} \neq}$ (D) and Andrea Menegon ${ }^{1^{*} \neq}$ (])
}

\begin{abstract}
Background: The increasing use of gold nanoparticles (AuNPs) in the field of neuroscience instilled hope for their rapid translation to the clinical practice. AuNPs can be engineered to carry therapeutics or diagnostics in the diseased brain, possibly providing greater cell specificity and low toxicity. Although there is a general enthusiasm for these tools, we are in early stages of their development. Overall, their brain penetrance, stability and cell specificity are critical issues that must be addressed to drive AuNPs to the clinic.

Results: We studied the kinetic, distribution and stability of PEG-coated AuNPs in mice receiving a single injection into the cisterna magna of the 4th ventricle. AuNPs were conjugated with the fluorescent tag Cy5.5 (Cy5.5-AuNPs) to track their in vivo distribution. Fluorescence levels from such particles were detected in mice for weeks. In situ analysis of brains by immunofluorescence and electron microscopy revealed that Cy5.5-AuNPs penetrated the brain parenchyma, spreading in the CNS parenchyma beneath the 4th ventricle. Cy5.5-AuNPs were preferentially found in neurons, although a subset of resting microglia also entrapped these particles.
\end{abstract}

Conclusions: Our results suggest that the ICM route for delivering gold particles allows the targeting of neurons. This approach might be pursued to carry therapeutics or diagnostics inside a diseased brain with a surgical procedure that is largely used in gene therapy approaches. Furthermore, this approach could be used for radiotherapy, enhancing the agent's efficacy to kill brain cancer cells.

Keywords: Gold nanoparticles, Intra cisterna magna, In vivo analysis

\section{Background}

A wide interest in the field of nanomedicine involves structurally different nanovectors, and in particular functionalized nanoparticles. Given their excellent biocompatibility and stability, nanoparticles are used to deliver drugs, genes, fluorescent labels, imaging agents, and

*Correspondence: muzio.luca@hsr.it; menegon.andrea@hsr.it ${ }^{\dagger}$ Antonello Spinelli and Maria Girelli contributed equally to this work ‡Luca Muzio and Andrea Menegon share senior authorship

${ }^{1}$ Experimental Imaging Centre, San Raffaele Scientific Institute, 20132 Milan, Italy

${ }^{2}$ Neuroimmunology Unit, Division of Neuroscience, Institute of Experimental Neurology (INSPE), San Raffaele Scientific Institute, 20132 Milan, Italy

Full list of author information is available at the end of the article enhancing radiotherapy tools. More recently, they were proposed as antiviral agents [1, 2]. Accordingly, more than 200 nano-objects targeted toward nanomedicine are currently approved for clinical trials in patients, while a larger number is engaged in pre-clinical studies [3].

Despite encouraging results indicate that nanovectors are reliable tools to treat a considerable number of pathologies, their use in disorders of central nervous system (CNS) is hampered by some limitations. A major challenge for their usage in CNS is their limited ability to cross the blood brain barrier (BBB), which often prevents to attain effective pharmacokinetic levels of therapeutics in the brain. Recent advances led to the generation of improved nanoparticles showing increased CNS penetration [4], therefore opening new avenues in basic and 
clinical neuroscience [5]. Among such particles, metallic nanoparticles are extremely attractive tools for their biophysical characteristics [6]. Gold nanoparticles (AuNPs) display unique optical and electronic properties to be considered reliable tools for drug/gene delivery, biomedical imaging [7], photothermal and microwave therapies [8]. AuNPs can be easily and uniformly functionalized with different chemical groups, allowing these particles to target specific locations in different organs as well as to reduce toxicity $[9,10]$. AuNPs display size-dependent kinetics and distribution when injected in tissues [11, 12]. The intravenous injection of AuNPs results in accumulation of particles in several organs, including the brain. Interestingly, particles with sizes in the range of $15-50 \mathrm{~nm}$ cross the BBB better than particles with bigger diameters $[12,13]$. The surface functionalization has a great impact on pharmacokinetic properties of AuNPs [4]. For example, transferrin-coated nanoparticles enter the brain through transcytosis and are more BBB-penetrant than other types of functionalized AuNPs [14]. Polyethylene glycol (PEG) coating of AuNPs increases their solubility and reduces toxicity [15]. Indeed, in a model of spinal cord contusion the local injection of PEG-coated AuNPs improved functional recovery and attenuated demyelination [16]. Insulin coated AuNPs crossed the $\mathrm{BBB}$, reaching the brain with concentrations that are around 5\% of the total injected dose [17]. However, 2 days after the delivery, the concentration of particles in the brain drops to values around $1-2 \%$ of the injected dose [13]. Imaging studies further corroborate these observations, showing that once AuNPs get into the brain, they rapidly disappear [17-21]. Intra-carotid injection of AuNPs increases the penetrance of particles in the brain, although their diffusion in the parenchyma is limited to few microns from the visible vessels [22]. Repeated treatments can increase the penetrating amount of AuNPs in the brain $[6,17,23]$, although an uncontrolled accumulation of AuNPs in neurons could create some adverse effects, such as alterations of the firing properties of neurons [24]. Therefore, we must take in consideration such aspect if we plan therapeutic strategies for chronic diseases/applications.

The use of intra-parenchymal injections or the implantation of catheters, both by-passing the $\mathrm{BBB}$, have the great limit of requiring invasive surgical procedures. Likely, both approaches can trigger undesired local inflammatory responses [25, 26]. A strategy to increase the penetrance and the permanence of appropriate concentrations of AuNPs in the CNS, that avoids the use of serial injections, requires alternative routes of administrations. In a model of focal lesion, such as the spinal cord injury, PEG-AuNPs injected in two sites that flanked the lesion epicenter efficiently supported the functional recovery of mice [16]. In spite of this noteworthy result, we can speculate that such procedure will find some limitations in diseases featuring large or disseminated brain lesions, such as multiple sclerosis (MS). Among alternative approaches to delivery AuNPs, the intrathecal route offers several advantages and it has been used to delivery drugs, as well as to infuse the brain with anesthetics, trophic factors and antibodies, although it has never been used to deliver nanoparticles [27, 28]. Experiments of gene delivery in mice clearly demonstrated that the intra cisterna magna (ICM) route is safe [29-31]. Indeed, gene therapy experiments showed that ICM injection of lentivirus leads viruses to diffuse consistently in all cerebrospinal fluid (CSF) spaces, infecting both choroidal and ependymal cells [29].

Growing evidence from several studies suggests that non-invasive imaging procedures to track the bio-distribution of AuNPs at different time points are excellent tools to accomplish the goal of using AuNPs in a clinical setting. The in vivo near infrared optical imaging of fluorescent-coated AuNPs is a relatively novel fluorescence imaging (FLI) approach that overcomes some previous limits of in vivo imaging, offering an excellent resolution and, above all, a limited invasiveness [17].

In this study, we characterized mice receiving ICM delivery of PEG functionalized and Cy5.5 labelled AuNPs (Cy5.5-AuNPs). We observed robust accumulation of Cy5.5-AuNPs in the CNS of mice, receiving a single injection of particles. Injected mice did not show signs of distress or pain. Remarkably, in vivo imaging showed detectable signals for more than 20 days. Confocal and electron microscopy analyses revealed that Cy5.5-AuNPs internalization in scattered neurons along the CNS parenchyma with some of them located several hundred microns far from the ependymal layer.

\section{Results}

\section{Synthesis and characterization of Cy5.5-AuNPs}

We recently developed a new method based on a Turkevich-modified 'one-pot' strategy to obtain large batches of functionalized AuNPs, that avoids the purification of intermediate citrate-stabilized nanoparticles [32]. PEG coating guarantees the indispensable colloidal stability and water dispersibility, making AuNPs undetectable by macrophages [33]. Taking advantage from this functionalization, we conjugated PEG-AuNPS with the near infrared fluorescent dye Cy5.5 (excitation/emission: 674/710 nm, having an ideal spectrum for in vivo imaging and limiting tissue auto-fluorescence). Purified Cy5.5-AuNPs were stable for months when kept at $4{ }^{\circ} \mathrm{C}$, without any trace of nanoparticles aggregation or Cy5.5. dye degradation as detected by DLS and fluorescence measurements. The obtained spherical Cy5.5-AuNPs 
showed a size distribution centered at $18.03 \pm 4.9 \mathrm{~nm}$ as determined by transmission electron microscopy (TEM) analysis (Fig. 1A). They showed the typical UV-vis spectrum with the maximum plasmonic absorption band at $523 \mathrm{~nm}$ (Fig. 1B). The presence of high molecular weight PEG coating the metal surface is confirmed by the determination of a hydrodynamic diameter value of $50.92 \mathrm{~nm}$ (Fig. 1C and Additional file 1: Figure S1) [34].

\section{In vitro characterization of Cy5.5-AuNPs toxicity}

We assayed the cytotoxicity of Cy5.5-AuNPs on primary neuronal cultures established from the hippocampus of E17.5 murine embryos. Neurons, cultured 15 days in vitro, exhibited the typical arborization of mature cells. At this time point, they usually display spontaneous neuronal activity organized in functional networks [35, 36]. We used FLI to establish fluorescence levels of a range of Cy5.5-AuNPs concentrations. We imaged plates containing increasing concentrations of particles and using $675 / 720$ filters we established a correlation between fluorescence levels and AuNPs concentrations (Fig. 2a, b). We next incubated neurons with increasing amount of Cy5.5-AuNPs to measure rates of cell death. Twentyfour hours after seeding neurons with particles, we evaluated percentages of dying neurons scoring Sytox ${ }^{+}$cells (Fig. 2c). We observed a slight increase of cell death rates in neurons receiving the highest concentration of Cy5.5AuNPs, although these levels did not statistically differ from values recorded in untreated neurons (Fig. 2c). However, lower concentrations of Cy5.5-AuNPs did percentages of Sytox ${ }^{+}$cells that not exceed rates measured in untreated cultures (Fig. 2c). We next fixed and labelled cells for NeuN and GFAP, which are markers of neurons and astrocytes respectively. We did not observe unspecific Cy5.5 signals in untreated cells (Fig. 2d, right column). Cultures receiving Cy5.5-AuNPs showed Cy5.5 fluorescence in regions containing clusters of $\mathrm{NeuN}^{+}$ cells. While the localization of Cy5.5 signals appeared uncorrelated with the distribution of $\mathrm{GFAP}^{+}$cells, (Fig. 2d left column). Altogether, these results suggests a general low cytotoxicity of PEG-coated Au particles for cultured hippocampal neurons [37].

\section{In vivo delivery of Cy5.5-AuNPs}

We next administered AuNPs to adult mice, establishing their pharmacokinetic distribution in the brain. We initially performed a single s injection of Cy5.5-AuNPs in the tail vein of mice. We used an equal amount of soluble Cy5.5 to establish control mice. We recorded FLI 5 days after the delivery of Cy5.5-AuNPs. We calculated the fluorescence ratio (FR) in each animal (see "Methods" sections for details). However, fluorescence levels measured in both groups did not exceed the background levels, and did not allow a robust calculation of FR levels (Additional file 2: Figure S2A). We next examined Cy5.5 fluorescence in the cortical wall of these mice using the NeuN marker to identify neurons. However, levels of Cy5.5 measured in both groups were did not exceed the general background (Additional file 2: Figure S2B and C).

We subsequently performed an intra parenchymal injection of Cy5.5-AuNPs targeting the presumptive somatosensory cortex of mice. Due to the small volume of Cy5.5-AuNPs that we delivered in brains, the fluorescence levels of Cy5.5 were hardly detectable in living mice. However, we detected signals that were more robust when we scored FLI in isolated brains collected 5 days after the injection of particles (Additional file 3: Figure S3A). Signals were concentrated in
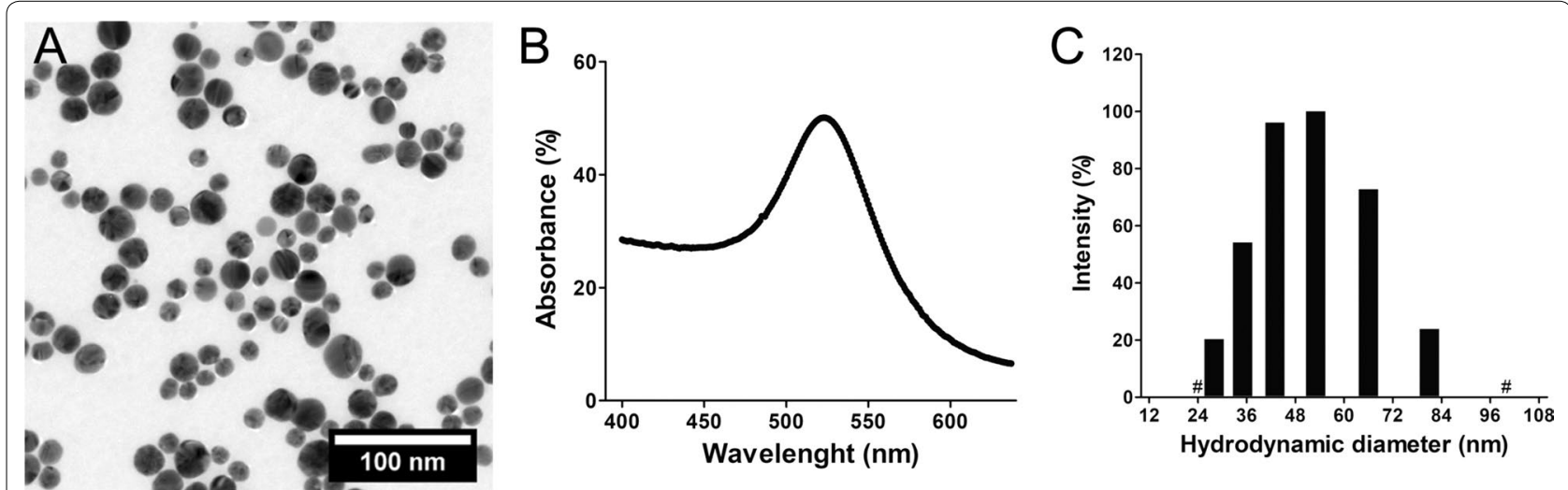

Fig. 1 Characterization of AuNPs. A TEM image of AuNPs. The AuNPs have a spherical shape with a diameter (mean \pm S.D.) of $18.03 \pm 4.93 \mathrm{~nm}$. B UV-vis spectrum of AuNPs. The maximum absorbance of the plasmonic peak is at $523 \mathrm{~nm}$. $\mathbf{C}$ Hydrodynamic diameter (nm) distribution of Cy5.5-AuNPs, obtained by dynamic light scattering (DLS) measurements. The intensity-mediated measure gives a mean hydrodynamic diameter of $50.92 \mathrm{~nm}$ 
Fig. 2 Cy5.5AuNPs do not elicit cytotoxicity in primary neuronal cultures. a Four representative plates of a 96 wells-plate containing $200 \mu \mathrm{l}$ of Cy5.5-AuNPs at four different concentrations that range from 1 to $0.001 \mathrm{mg} / \mathrm{ml}$. Images were acquired using the 675/720 filters and averaged radiant efficiencies were measured using a circular ROI superimposed on each well. Histogram of $\mathbf{b}$ shows the linearity between the radiant efficiency and AuNPs concentration. $\mathbf{c}$ Percentages ( \pm S.D.) of dying hippocampal neurons in cultures treated with AuNPs. Percentages ( \pm S.D.) of dying cells, scored with Sytox, are shown on $\mathbf{c}$. Inset shows a representative picture derived from cultures receiving AuNPs for $24 \mathrm{~h}, \mathrm{n}=4$ independent cultures. $\mathbf{d}$ Au-NPs distribution in hippocampal cultures receiving $0.1 \mathrm{mg} / \mathrm{ml}$ of Cy5.5-NPs for $24 \mathrm{~h}$. Cultures were labelled for GFAP to identify astrocytes (upper row d) and NeuN to identify neurons (lower row d). Scale bar $15 \mu \mathrm{m}$ for c and $40 \mu \mathrm{M}$ for $\mathbf{d}$

spots localized in the presumptive somatosensory cortex (Additional file 3: Figure S3A). FLI of $500 \mu \mathrm{m}$ thick coronal slabs further confirmed that highest Cy5.5 signal was deriving from the somatosensory cortex (Additional file 3: Figure S3B). AuNPs with a size of $20 \mathrm{~nm}$ absorb $530 \mathrm{~nm}$ wavelength and emit a wavelength that peaks at $610 \mathrm{~nm}$, which is sufficiently intense to be detected by a fluorescence microscope [38]. Therefore, we performed serial imaging of adjacent sections, scoring the somatosensory cortical wall. We labelled $20 \mu \mathrm{m}$ thick sections for NeuN and by confocal microscopy we observed the almost perfect co-localization of Cy5.5 signals with Au signals (Additional file 4: Figure S4A, B) in several cortical $\mathrm{NeuN}^{+}$cells (Additional file 4: Figure S4C, D).

We next labelled parallel sections for the microglia/ macrophages Iba1 to establish whether the injection procedures may alter the cortical morphology. We used Iba1 to label reactive microglia/macrophages, both associated to focal CNS injuries [39]. Iba1 ${ }^{+}$cells were scored in regions surrounding the site of the injection (ipsilateral cortex) as well as in the controlateral cortex, not receiving any manipulation (Additional file 3: Figure S3C, D). We observed a moderate to high gliosis featured by a significant increase of $\mathrm{Iba}^{+}$cells in the ipsilateral cortex (Additional file 3: Figure S3E). Therefore, we reasoned that the relative high abundance of $\mathrm{Iba}^{+}$Cy5.5-AuNPs ${ }^{+}$cells in the ipsilateral cortex could mirror the activation of phagocytosis (Additional file 3: Figure S3F), a classical phenomenon that occurs in response to tissue damage [40].

We next performed ICM delivery of either Cy5.5AuNPs or the unconjugated Cy5.5 [41]. Upon Cy5.5AuNPs injections, we performed FLI analysis of Cy5.5 at different time points. Intense Cy5.5 fluorescence signals were detected in regions encompassing the 4th ventricle of mice injected with Cy5.5-AuNPs (Fig. 3a). Calculated FR levels peaked 1 day after the injection, although a

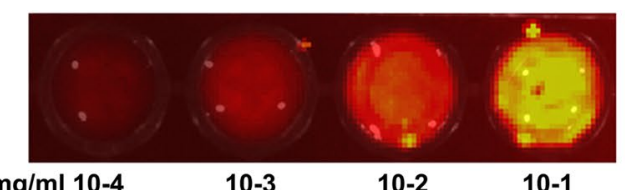

b

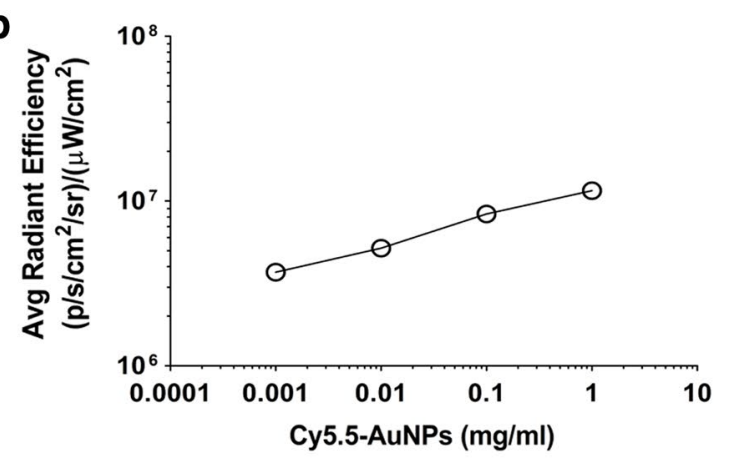

C

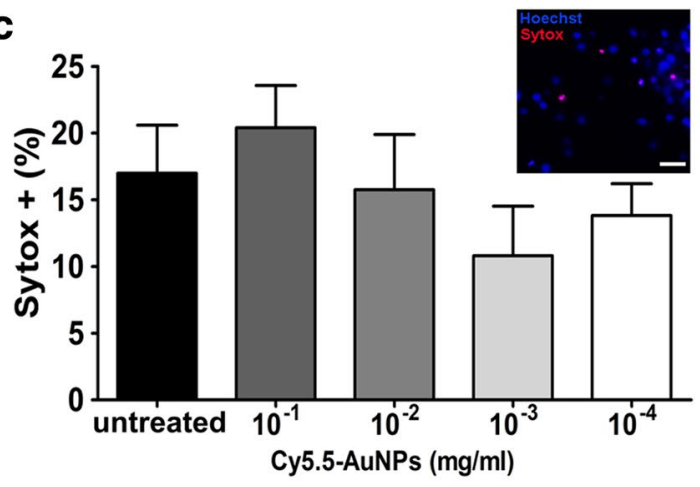

d

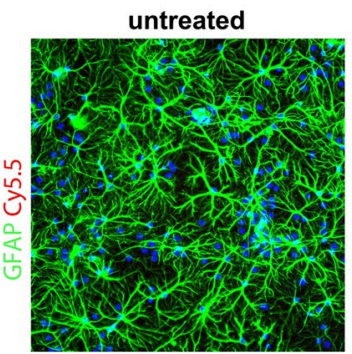

Cy5.5-AuNPs
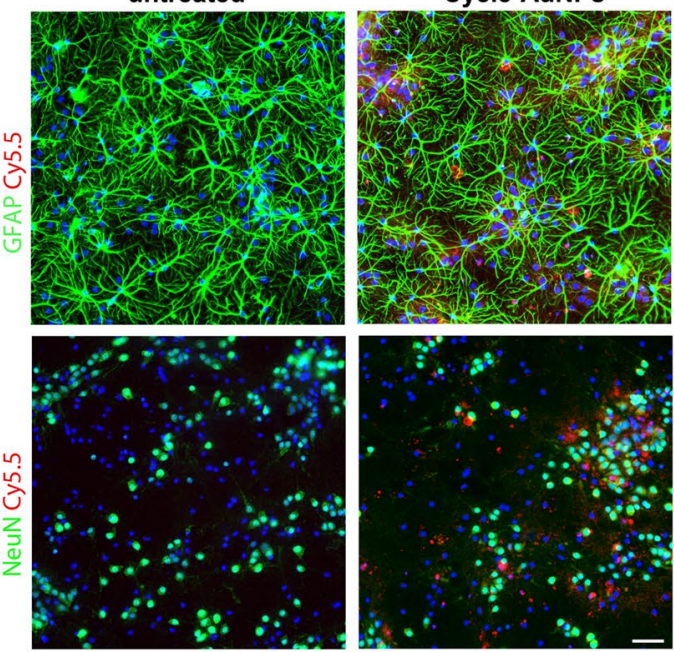

considerable high fluorescence signals were still detectable 25 days after the injection (Fig. 3c). On the other hand, scant fluorescence levels were observed in mice treated with the unconjugated Cy5.5 (Fig. 3b, d). 


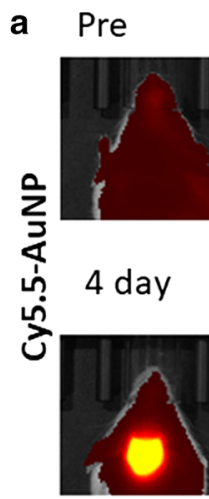

$1 \mathrm{~h}$

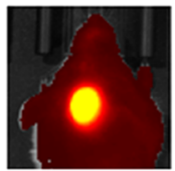

7 day

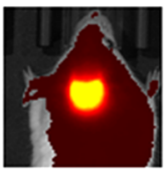

b Pre

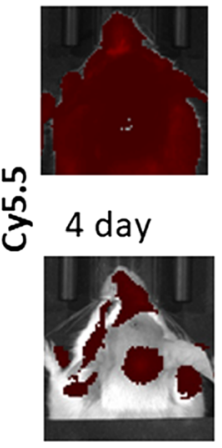

$1 \mathrm{~h}$

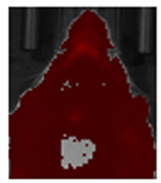

7 day

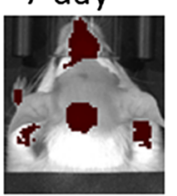

1 day

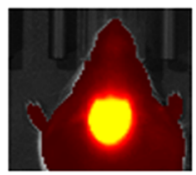

10 day

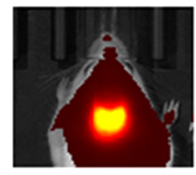

1 day

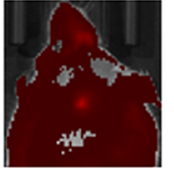

10 day

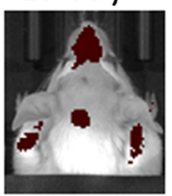

2 day

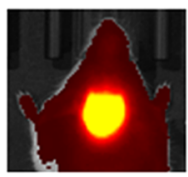

16 day

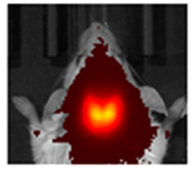

2 day

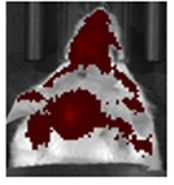

16 day

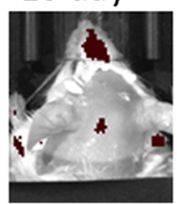

Epi-fluorescence $\left(x 10^{8}\right)$

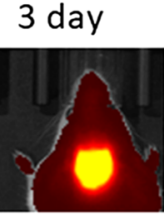

25 day

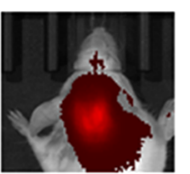

3 day

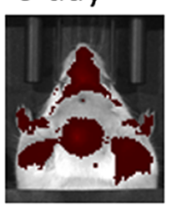

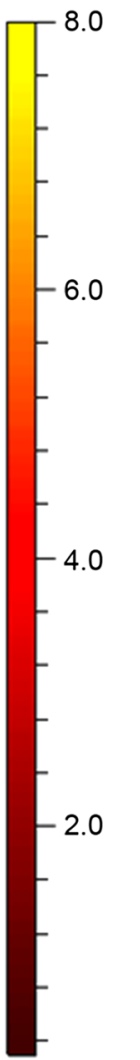

C

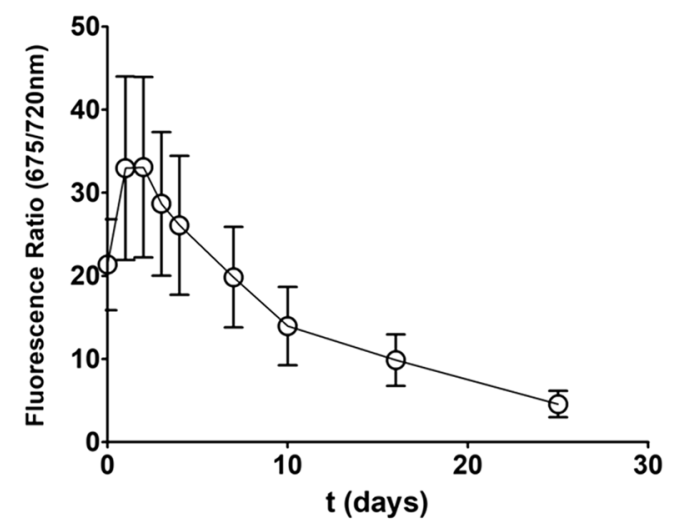

Fig. 3 Longitudinal distribution of AuNPs in ICM-injected mice. a FLI imaging of a single animal receiving ICM injection of Cy5.5-AuNPs. Pictures were recorded at different time points ( $1 \mathrm{~h}, 1,2,3,4,7,10,16$ and 25 days after the injection). FLI levels recorded in a control animal receiving ICM injection of unconjugated Cy5.5 are shown in $\mathbf{b}$. The epi-fluorescence scale used in both experiments is shown on the right side of the panel. Plots in $\mathbf{c}$, $\mathbf{d}$ show quantifications of FR levels (mean \pm S.D.) in mice receiving Cy5.5-AuNPs (c) as well as in mice receiving soluble Cy5.5 (d), $(n=3$ for each group)

We next calculated Au concentrations in brain explants obtained from mice receiving ICM injection of Cy5.5AuNPs. The Cy5.5-injected group was not included in this experiment since we reasoned that FR signals were close to background levels as shown in the previous experiment (Fig. 3d). Two and five days upon Cy5.5-AuNPs delivery, mice were perfused with saline to remove particles potentially retained in the blood 


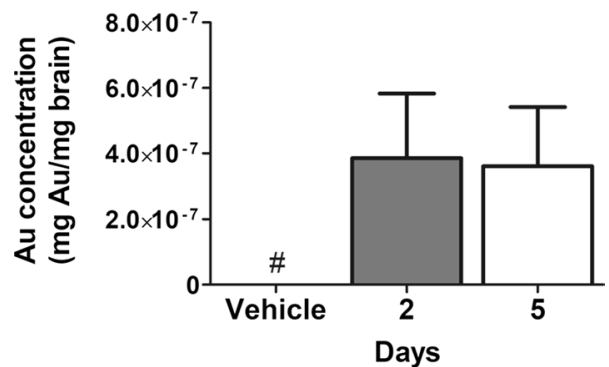

Fig. 4 ICP-OES analysis of brain Au contents. Adult mice received ICM injections of Cy5.5-AuNPs or vehicle and brains were collected 2 and 5 days after the delivery ( $n=3$ for each group). Plot reports means ( \pm S.D.) of the total amount of $\mathrm{Au}(\mathrm{mg})$ found in the brain homogenates $(\mathrm{mg})$ at each time point

circulation. We dissected each brain to obtain coronal slabs that spanned from the anterior bregma -5.5 to the posterior bregma - 8.5. Explants were digested over a heating plate by adding a solution of $\mathrm{HNO}_{3} / \mathrm{H}_{2} \mathrm{O}_{2}$ $30 \% \mathrm{~m} / \mathrm{m}(3 / 1)$ followed by aqua regia, and the amount of $\mathrm{Au}$ in each of them was detected by Inductively Coupled Plasma-Optical Emission Spectrometers (ICP-OES). $\mathrm{Au}$ was undetectable in vehicle-treated mice, while a significant amount of Au was detected in Cy5.5-AuNPs injected mice at both time points (Fig. 4).

\section{Ex-vivo localization of Cy5.5-AuNPs in ICM injected brains}

We next investigated the uptake of Cy5.5-AuNPs in fixed brains sections, sampling brains from mice sacrificed 30 days after ICM delivery of Cy5.5-AuNPs. Using confocal microscope, we acquired Cy5.5 and Au fluorescence in order to increase the signal to noise ratio, the signal specificity, and to provide a better estimation of Cy5.5AuNPs distribution [38]. We scored scattered $\mathrm{NeuN}^{+}$ cells in the presumptive medial vestibular nucleus that were positive for Cy5.5-AuNPs (Fig. 5A, B). Conversely, sections labelled for GFAP (Fig. 5C, D) and for the myelin marker MBP (Fig. 5E, F) showed very few, if any, cells containing Cy5.5-AuNPs. We next labelled sections for Ibal and we observed some putative microglia displaying the ramified cell morphology of bona fide resting cells that were positive for Cy5.5-AuNPs (Fig. 5G, H). Control brains derived from mice injected with soluble Cy5.5 did not show any detectable signal for Cy5.5 and Au (Fig. 5A, $\mathrm{C}, \mathrm{E}$ and $\mathrm{G}$ ). We next assessed the localization of Cy5.5AuNPs in the CNS by TEM, sampling sections in a region encompassing the 4th ventricles. Cy5.5-AuNPs were observed in few ependymal cells (not shown), while we observed particles in parenchymal cells. Nanoparticles were detected in some electron dense vacuoles, possibly belonging to lysosomal compartment (Fig. 5I). We next calculated percentages of $\mathrm{NeuN}^{+} \mathrm{Cy} 5.5^{+} \mathrm{Au}^{+}$cells in the pons/medulla of ICM-injected mice that we sacrificed at day 15 (Fig. 6A, C). Control mice injected with unconjugated Cy5.5 displayed signals that were undistinguishable from background levels (Fig. 6A, C). On the other hand, we observed intense Cy5.5 levels in mice receiving particles (Fig. 6B). We next went to the tissue scoring $\mathrm{Au}$ and $\mathrm{Cy} 5.5$ in NeuN-expressing cells located in the pons/medulla, a region placed beneath the 4th ventricles (boxed area of Fig. 6D). Around 23\% of $\mathrm{NeuN}^{+}$cells showed $\mathrm{Au}$ and Cy5.5 signals in the cytoplasm (Fig. 6E, F). Of note, some triple positive cells were relatively far from the ventricular lining, suggesting that AuNPs can spread in the CNS parenchyma (arrows in Fig. 6D).

\section{Discussion}

A considerable number of putative drugs lacks the ability to penetrate the $\mathrm{BBB}$, and for this limitation none of them were further pursued as therapeutics. The functionalization of nanovectors with these molecules could, in principle, overcome such limitation, allowing their diffusion in diseased brains. Thus, the physiological barrier represented by the BBB could be crossed by nanoparticle-supported drugs able then to interact with their targets. However, after an initial enthusiasm for this approach, it became clear that the general efficiency of nanovectors to cross the BBB was modest [17-21]. In this context, AuNPs have attracted attention for their safety and biophysical characteristics [42]. The direct injection of AuNPs in the CNS parenchyma is attractive, although our data indicate that such procedure may generate tissue damage and microglia activation. Intranasal administration of AuNPs, conversely, leads to their uptake in different brain regions and is a promising method for the $\mathrm{BBB}$ passage of nanoparticles, although the regional distribution in the brain of molecules may vary from substance to substance, and additional studies are needed to validate this approach [43]. Repeated intravenous injections of nanoparticles, often using high dosages to achieve BBB permeation, could induce their accumulation in the liver causing inflammation and apoptosis and may alter neuronal functions [41, 44]. A recent study, showing in vivo instability of coated AuNPs, adds a further layer of complexity, suggesting that using AuNPs to deliver molecules as well as their tracking in living animals may be influenced by a certain degree of molecular instability and/ or cell metabolism [45]. Indeed, fluorochrome-coated AuNPs are processed by lysosomes in the liver, and molecules tagging AuNPs can be cleaved by proteolysis [45]. These experimental observations should be considered in the interpretation of distribution studies after systemic administration of AuNPs.

For these reasons, we attempted to deliver Cy5.5AuNPs directly in the brain using a single intrathecal 

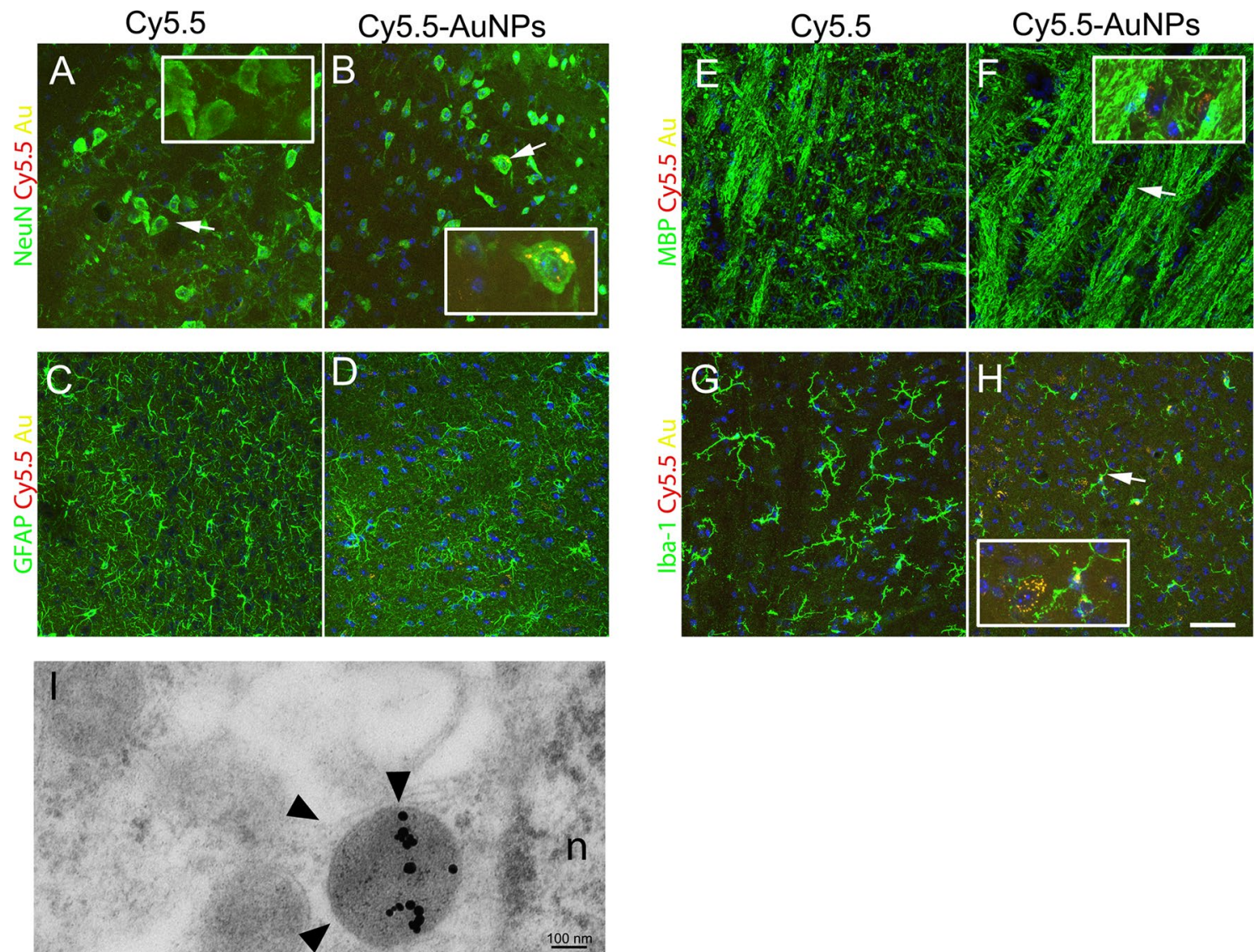

Fig. 5 Distribution of Cy5.5-AuNPs in ICM-injected mice. Confocal images of sections (maximum projections) from the pons/medulla of mice sacrificed 30 days after ICM injections. Acquisitions were done to capture Cy5.5 and Au signals in control mice-i.e. receiving Cy5.5 (A, C, E and G) - and in mice receiving Cy5.5-AuNPs (B, D, F and H). A, B Triple labelling for NeuN, Cy5.5 and Au. Arrows indicate cells that are shown at high magnifications in insets. C, D Confocal images of adjacent sections labelled for Cy5.5, Au and GFAP. E, F Triple labelling for MBP, Cy5.5 and Au. Arrow in $\mathbf{F}$ indicates a region that is shown at high magnification in the inset. G, $\mathbf{H}$ Confocal images of sections labelled for Iba1, Cy5.5 and Au. The arrow in $\mathbf{H}$ indicates one $\mathrm{Iba}^{+}$cells that is shown at high magnification in the inset ( $\mathrm{n}=3$ for each group). I Au nanoparticles localized in vacuoles of parenchymal cells of brains sampled at day 15. Arrows indicate several Au particles in a putative lysosome of a cell $(n=2)$. Scale bar $50 \mu m$ for $\mathbf{A}-\mathbf{H}$, $0.1 \mu \mathrm{m}$ for I

injection. This approach has been extensively used in the past to deliver lentiviral particles and drugs [30]. ICM injections are well characterized for such vectors, but little is known regarding their use to deliver AuNPs. Our experimental evidence shows that this route of administration does not induce signs of distress in mice. It was surprising to observe, using in vivo optical imaging, that mice receiving Cy5.5-AuNPs showed retention of particles in the brain for more than 20 days. Furthermore, in this experimental setting we observed that the fluorescence emitted by both Cy5.5 and Au in brain sections were perfectly overlapped, suggesting a high stability of the Cy5.5 tag grafted on Au surfaces. These results suggest that functionalized AuNPs entering the CNS escape the degradation and are more stable in the CNS than in other organs, such as the liver [45]. The diffusion of Cy5.5-AuNPs in the CNS parenchyma was surprisingly wide, and some neurons positive for them localized several hundreds of microns away from the ventricular cavity. The mechanism of diffusion of such particles is still unknown, but we could speculate that these such small particles can passively diffuse in the extracellular matrix before being up taken by endocytosis. However, double staining of Cy5.5-AuNPs and markers of neurons, microglia and astrocytes, revealed that AuNPs uptake was prominent in neurons, while only few microglia efficiently incorporate such particles. The high stability of Cy5.5-AuNPs in the brain can be due to their rapid uptake by cells, that prevents their removal by convective lymphatic fluxes of the CSF [46]. In addition, PEG functionalization is helping to prevent their uptake by peri-vascular macrophage, thus increasing the half-life of Cy5.5-AuNPs. Thus, our study clarifies the routes and the mechanisms of functionalized AuNPs distribution, 

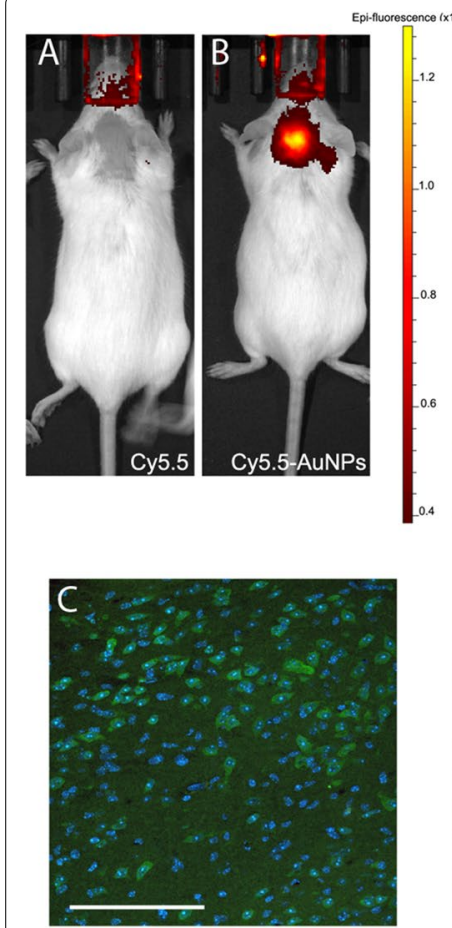

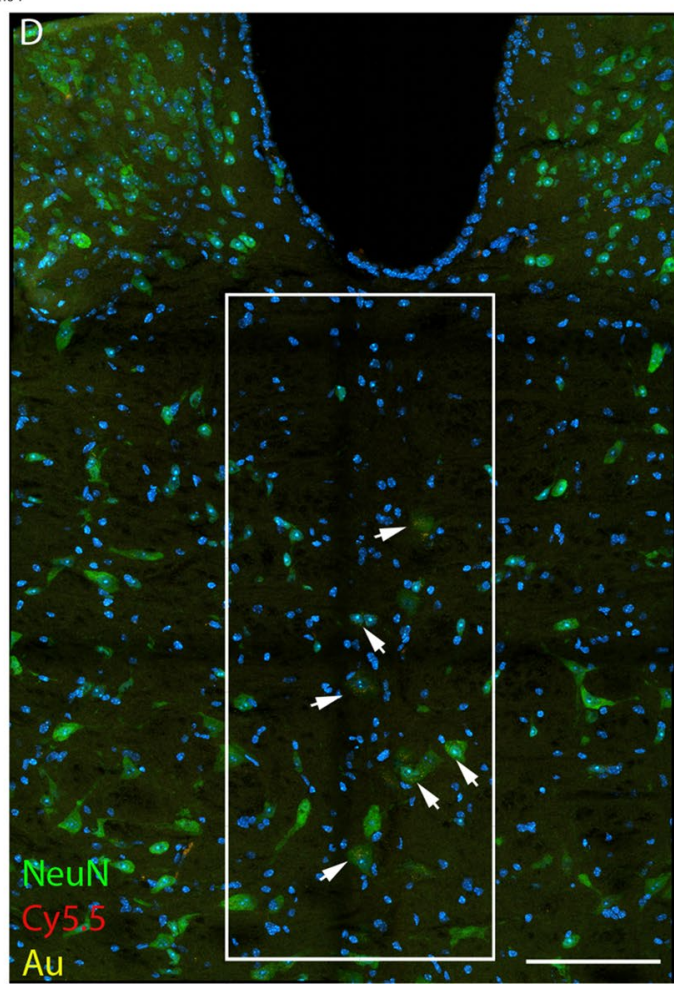

Fig. 6 Distribution of Cy5.5-AuNPs ${ }^{+} \mathrm{NeuN}^{+}$in ICM-injected mice. A, B FLI scans in a control mouse (Cy5.5) and in a mouse receiving Cy5.5-AuNPs both sacrificed 15 days after the injection. The Epifluorescence scale is plotted on the right side of $\mathbf{A}$. Representative confocal scans for NeuN, Cy5.5 and $\mathrm{Au}$ in the pons/medulla of these mince are shown in $\mathbf{C ,} \mathbf{D}(n=3$ for each group). $\mathbf{D}$ Is a confocal image obtained stitching six independent pictures. Percentages of $\mathrm{NeuN}^{+} \mathrm{Cy} 5.5^{+} \mathrm{Au}^{+}$were established in mice receiving Cy5.5-AuNPs scoring cells in the superimposed $\mathrm{ROI}(200 \times 500 \mu \mathrm{m})$ and data are plotted in $\mathbf{E}$. Arrows of $\mathbf{D}$ show NeuN ${ }^{+} \mathrm{Cy} 5.5^{+} \mathrm{Au}^{+}$cells. F A confocal cross section of a NeuN ${ }^{+}$cells expressing Au and Cy5.5. Scale bar $100 \mu \mathrm{m}$ for $\mathbf{C}, \mathbf{D}$ and $10 \mu \mathrm{m}$ for $\mathbf{F}$

kinetic and stability after entering the brain. We observed a relevant AuNPs uptake in neurons and microglia far from the CM. We also observed their uptake in intracellular compartments (mainly lysosomes), suggesting a movement of Cy5.5-AuNPs through membrane compartments.

\section{Conclusion}

We have demonstrated that Cy5.5-AuNPs are highly stable upon their entry into the CNS, probably due to their resistance to cellular metabolism. We have shown that AuNPs are efficiently taken up by neurons and concentrate into intracellular compartments. In principle, their long stability and their ability to target intracellular vesicles in neurons could be exploited in disorders showing disrupted lysosomal homeostasis in neurons, such as the wide family of Lysosomal Storage Diseases [47]. AuNPs could be also exploited in brain cancer radiotherapy, because PEG-coated AuNPs can accumulate in brain tumors and can be efficiently used for increasing radiotherapy efficiency [8]. Thus, our experimental evidence showing a long-lasting PEG-AuNPs accumulation in neurons upon intrathecal injection suggests that this route of administration could be potentially used for radiotherapy enhancing agents in CNS tumors as well as in Lysosomal Storage Diseases.

\section{Methods}

\section{Synthesis of PEG-functionalized AuNPs}

Synthesis of PEG-functionalized AuNPs was performed following our published methods [32]. Cyanine 5.5 (Cy5.5) NHS ester was purchased from Lumiprobe (Hunt Valley, Maryland 21030, USA) and stored in the dark at $-20{ }^{\circ} \mathrm{C}$. All glassware used for AuNP synthesis was cleaned with aqua regia $(\mathrm{HCl}(37 \%) /$ $\left.\mathrm{HNO}_{3}(65 \%) 3 / 1\right)$. A water mixture of sodium citrate $(9 \mathrm{ml}, 2 \%), \mathrm{HAuCl}_{4}{ }_{3} \mathrm{H}_{2} \mathrm{O}(7.0 \mathrm{ml}, 10 \mathrm{mM})$ and $\mathrm{AgNO}_{3}$ (420 $\mu \mathrm{l}, 0.1 \%)$ was stirred at room temperature for $6 \mathrm{~min}$ and added to $250 \mathrm{ml}$ of boiling water. The mixture was stirred $(750 \mathrm{rpm})$ for $1 \mathrm{~h}$ at $100{ }^{\circ} \mathrm{C}$, then the 
seed solution was allowed to cool to room temperature. Glycerol $(5 \mathrm{ml})$ was added and the suspension was stirred for $15 \mathrm{~min}$. A second aliquot of sodium citrate $(10 \mathrm{ml}, 1 \%), \mathrm{HAuCl}_{4}(7.5 \mathrm{ml}, 10 \mathrm{mM})$ and $\mathrm{AgNO}_{3}$ $(426 \mu \mathrm{l}, 0.1 \%)$ was separately stirred for $6 \mathrm{~min}$ and then added to the colloidal solution, followed immediately by a solution of hydroquinone $(8 \mathrm{ml}, 1 \%)$. The resulting solution was allowed to age, stirring at $750 \mathrm{rpm}$ for $1 \mathrm{~h}$ at room temperature. The reddish solution of citrate-capped AuNPs was directly used without purification to functionalize the gold surface. A mixture of $\mathrm{CH}_{3} \mathrm{O}-\mathrm{PEG}_{5000}-\mathrm{SH} / \mathrm{NH}_{2}-\mathrm{PEG}_{5000}-\mathrm{SH}$ 9/1 (30 mg, Rapp Polymer $\mathrm{GmbH}$ ) was dissolved in $5 \mathrm{ml}$ of water and $\mathrm{NaOH}(8 \mathrm{mg})$ and added to the mixture containing AuNPs while argon was bubbled in the solution (for $5 \mathrm{~min}$ ). The reaction mixture was stirred for $48 \mathrm{~h}$ at room temperature. PEG-AuNPs were then concentrated and purified by mean of Amicon centrifugal Filter units to a final volume of $11 \mathrm{ml}$.

\section{Synthesis of Cy5.5-AuNPs}

Five ml of PEG-functionalized AuNPs (10\% PEG- $\mathrm{NH}_{2}$ ), in milliQ water, were filtered by centrifugal filtration $(10,000$ MWCO, Vivaspin filters) to remove the solvent, and were re-suspended in borate buffer at $\mathrm{pH}$ 8. To this solution, Cy5.5-NHS ester (450 $\mu \mathrm{g}, 0.00063 \mathrm{mmol}$, LumiprobeHunt Valley, Maryland 21030, USA) dissolved in DMSO $(500 \mu \mathrm{l})$ was added at room temperature. We adjusted $\mathrm{pH}$ to 8.5 by adding $\mathrm{NaOH} 0.2 \mathrm{~N}$, and the reaction mixture was stirred at room temperature in the dark for ca. $18 \mathrm{~h}$. Then, the solvent was removed by centrifugal filtration (10,000 MWCO, Vivaspin filters) and Cy5.5-AuNPs were washed with $\mathrm{tBuOH} / \mathrm{H}_{2} \mathrm{O}$ 1:1 until the collected washing solution was colorless (the absence of Cy5.5 adsorption was checked through UV-Vis spectroscopy). Finally, Cy5.5-AuNPs were washed with milliQ water to remove $\mathrm{tBuOH}$ traces, were dissolved in $5 \mathrm{ml}$ milliQ water and stored at $4{ }^{\circ} \mathrm{C}$.

\section{Characterization of Cy5.5-AuNPs}

Dynamic light scattering (DLS) was employed to measure hydrodynamic diameter and Zeta-potential, determined by using a 90 Plus Particle Size Analyzer from Brookhaven Instrument Corporation (Holtsville, NY) operating at $15 \mathrm{~mW}$ of a solid-state laser $(\lambda=661 \mathrm{~nm})$, using a scattering angle of $90^{\circ}$, equipped with an AQ-809 electrode, operating at applied voltage of $120 \mathrm{~V}$. DLS samples were prepared by filtration with a $0.45 \mu \mathrm{m}$ cellulose acetate syringe filter before loading into the cuvette, in order to remove large interfering particulate matter. Each sample was allowed to equilibrate for $3 \mathrm{~min}$ prior to start the measurement. Three to ten independent measurements of $60 \mathrm{~s}$ duration were performed, at $25^{\circ} \mathrm{C}$. The hydrodynamic diameter calculation was performed using Mie theory. The absolute viscosity and refractive index values of the medium were respectively set to $0.911 \mathrm{cP}$ and 1.334 . The Zeta-potential was automatically calculated from electrophoretic mobility based on the Smoluchowski theory. A viscosity of $0.891 \mathrm{cP}$, a dielectric constant of 78.6, and a Henry function of 1.5 were used for the calculations. UV/Vis spectra were recorded on an Agilent 8453 instrument by using a disposable cuvette with $1 \mathrm{~cm}$ optical path length for the measurements. Transmission electron microscopy micrographs have been collected using a TEM-Zeiss LIBRA 200FE instru-

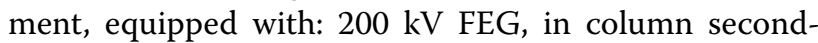
generation omega filter for energy selective spectroscopy (EELS) and imaging (ESI), HAADF STEM facility, EDS probe for chemical analysis, integrated tomographic HW and SW systems. TEM specimens were prepared by dropping an aqueous solution of AuNPs onto a carboncoated copper grid (300 mesh) and evaporating the solvent. The particle size distribution was estimated by using ITEM-TEM Imaging platform-Olympus Soft Imaging Solutions. The number of measured nanoparticles for each sample resulted to be around 250. Au concentration was determined via Inductively Coupled PlasmaOptical Emission Spectrometers (ICP-OES; iCAP 6300 Duo, Thermofisher). Samples (1 $\mathrm{ml}$ each) were digested in a glass vial over a heating plate with aqua regia $(2 \mathrm{ml})$, repeating the treatment for four times. The explant samples were digested over a heating plate with a solution of $\mathrm{HNO}_{3} / \mathrm{H}_{2} \mathrm{O}_{2} 30 \% \mathrm{~m} / \mathrm{m}(3 / 1,2 \mathrm{ml})$ for two times, followed by aqua regia $(2 \mathrm{ml})$ for three times. The dry residues were dissolved in a $0.5 \mathrm{M} \mathrm{HCl}$ aqueous solution and diluted. The limit of detection (lod) calculated for gold was $0.01 \mathrm{ppm}$.

\section{Nanoparticle administration in vivo}

Mice were maintained under pathogen-free conditions at San Raffaele Hospital mouse facility (Milan, Italy). All efforts were made to minimize animal suffering and to reduce the number of mice used in accordance with the European Communities Council Directive of 24 November 1986 (86/609/EEC). Five weeks CD1 (Charles Rivers) females were given an injection of anesthetic (2,2,2-tribromoethanol, $10 \mathrm{mg} / \mathrm{ml}$; $1 / 27$ of body weight), then $10 \mu \mathrm{l}$ of Cy 5.5 -AuNPs $(0.11 \mu \mathrm{g} / \mu \mathrm{l})$ were injected within the cisterna magna of mice using a 27 -gauge stainless steel needle curved $\left(40^{\circ}\right)$ at $3.5 \mathrm{~mm}$ from the tip, so that it was J-shaped [48]. IV delivery was obtained injecting mice in the tail vein with $200 \mu \mathrm{l}$ of Cy5.5-AuNPs $(0.11 \mu \mathrm{g} /$ $\mu \mathrm{l})$. Intra parenchymal injection was obtained by delivering $1 \mu \mathrm{l}$ of Cy 5.5 -AuNPs $(1.1 \mu \mathrm{g} / \mu \mathrm{l})$ in the brain by a single stereotaxic injection at the following coordinates: A 
$-0.5,0 ; \mathrm{L},+1.2$; and $\mathrm{D},-0.8$ [49]. Control mice received injections of soluble Cy5.5 or vehicle (sterile saline). To calculate the appropriate amount of Cy5.5 to be delivered into the cisterna magna, we compared curves of fluorescence from serial dilutions (dilution factor $=10$ ) of Cy5.5 and Cy5.5-AuNPs, using the IVIS SpectrumCT System. Control mice received Cy5.5 at the concentration that produced the same fluorescence level of the Cy5.5-AuNPs used in our experiments. At the sacrifice $(2,5,15$ and 30 days after the delivery of particles), mice were given an overdose of anesthetic drugs and were transcardially perfused with saline followed by $80 / 100 \mathrm{ml}$ $4 \%$ paraformaldehyde in PBS $1 \times, \mathrm{pH} 7.2$ (Sigma). Brains were post fixed in the same solution for $12 \mathrm{~h}$ at $+4{ }^{\circ} \mathrm{C}$. Tissues were cryoprotected in PBS/30\% Sucrose (Sigma), embedded in OCT inclusion media and stored at $-80^{\circ} \mathrm{C}$ before processing. The metal content in brain explants was determined by ICP-OES. Mice were perfused with sterile saline and brains homogenized in PBS solutions. Sample were digested in a glass vial over a heating plate with aqua regia according our published methods [32]. The dry residuals were dissolved in a $\mathrm{HCl}$ aqueous solution $0.5 \mathrm{M}$ and properly diluted.

\section{In vivo imaging}

Mice images were acquired by placing the animals at $37{ }^{\circ} \mathrm{C}$ under gaseous anesthesia $(2-3 \%$ isoflurane and $1 \mathrm{l} / \mathrm{min}$ oxygen). FLI was performed by IVIS SpectrumCT System (Perkin Elmer), equipped with a low noise, back-thinned, back-illuminated CCD camera cooled at $-90{ }^{\circ} \mathrm{C}$ and a with quantum efficiency in the visible range $>85 \%$. Images were obtained using the following settings: exposure time $=$ auto, binning $=8, \mathrm{f}=2$ and a field of view equal to $13 \mathrm{~cm}$ (field $\mathrm{C}$ ); when needed spectral unmixing, FLI was obtained using the following excitation/emission filters: 640/680, 640/700, 640/720, 640/740, 675/720, 675/740, 675/760 nm. Acquisitions were done before and after the injection of particles with the following time sampling: $1 \mathrm{~h}$, and $1,2,3,4,7$, 10, 16, 25 days after the delivery of Cy5.5-AuNPs. Analyses were done in a region of interest (ROI) overlapping the brain, measuring the radiant efficiency within this ROI using images acquired with the $675 / 720$ filters. The FR $\left(t_{i}\right)$ was calculated on ROI sampled at different time points $\left(t_{i}\right)$ and normalized on images acquired before injection or particles $\left(t_{0}\right)$ to quantify the magnitude of the fluorescence signal: $\mathrm{FR}\left(\mathrm{t}_{\mathrm{i}}\right)=\left[\mathrm{ROI}\left(\mathrm{t}_{\mathrm{i}}\right)\right) /\left(\mathrm{ROI}\left(\mathrm{t}_{0}\right)\right]$. Spectral un-mixing of the FLI data was performed on selected images in order to show the specificity of the fluorescence signal over the tissue auto-fluorescence. All the images were acquired and analyzed using Living Image 4.5 (Perkin Elmer).

\section{Immunofluorescence and electron microscopy}

Immunofluorescence and electron microscopy have been done according the following methods [49-51]. Brains were sagittal or coronal sectioned $(20 \mu \mathrm{m})$ and one section every $250 \mu \mathrm{m}$ was used for immunofluorescence. Slides were washed in PBS $1 \times$ and incubated with the following blocking buffer: PBS $1 \times$, BSA $1 \mathrm{mg} / \mathrm{ml}$, FBS $10 \%$, Triton $0.1 \%$ (Sigma). Primary antibodies were diluted in the same buffer and incubated on section for $12 \mathrm{~h}$ at $+4{ }^{\circ} \mathrm{C}$. Secondary antibodies (Alexa-flour conjugated) were incubated according to manufacturer' instructions, then sections were cover slipped with Dako mounting mix. The following antibodies were used: mouse $\alpha-\mathrm{NeuN}$ (Millipore, 1:800); rabbit $\alpha$-MBP (Millipore) 1: 500; rabbit $\alpha$-Iba1 (Wako) 1:400; rabbit $\alpha$-GFAP (Dako) 1:1000. Secondary, Alexafluor 488-conjugated antibodies were used according to manufactures' instructions. Acquisitions were performed with a Leica SP8 confocal microscopy equipped with a $40 \times$ objective and with super-sensitive $\mathrm{HyD}$ detectors. Fluorescence was recorded as square 8-bit images $(1024 \times 1024$ pixels $)$ and stored as separate image stacks for each channel. Alignment of images to obtain largest field of view of coronal sections was done by automatic stitching of stack images using the Leica (Las-X, Leica). Acquisition of fluorescence from Au was done according published methods [38]. We used an excitation wavelength of $532 \mathrm{~nm}$, while signals were acquired in the 594-640 $\mathrm{nm}$ window. Images showed the maximal projections of Z-stacks acquired with a $0.8 \mu \mathrm{m}$ step or cross sections of selected cells acquired with $0.3 \mu \mathrm{m}$ step. Images were pseudo-colored using Las-X software. For EM analysis, brains were post-fixed in $0.12 \mathrm{M}$ phosphate buffer supplemented with $2 \%$ glutaraldehyde, and further sectioned to get a region encompassing the 4th ventricle and the cerebellum. These parts were further post-fixed with osmium tetroxide and embedded in Epon (Fluka, Buchs, Switzerland). Ultrathin sectioning of the CNS allowed the generation of $70 \mathrm{~nm}$ sections that were imaged by a transmission electron microscope (LEO 912AB). In vitro quantification of Cy5.5-AuNPs fluorescence were performed using the FLI (FLI) acquired with IVIS SpectrumCT System scanner (Perkin Elmer).

\section{Primary hippocampal cultures and sytox determination}

Neurons were obtained from the hippocampus of CD1 (Charles Rivers) mice at the embryonic stage of E17.5. Hippocampi were mechanically dissociated in cold HBSS supplemented with $0.6 \%$ glucose, $5 \mathrm{mM}$ HEPES ( $\mathrm{pH}$ 7.4) (Sigma Aldrich). Cells were suspended in culture medium containing Neurobasal Medium (Thermo Fisher Scientific) supplemented with: N2 (Thermo Fisher Scientific), B27 (GIBCO), 5 mM HEPES (pH 7.4), 0.6\% glucose 
(Sigma Aldrich) and 0.5\% glutamine (Thermo Fisher Scientific) in the absence of antimitotic and antibiotic drugs. Fifteen days after plating neurons were incubated with increasing amounts of Cy 5.5-AuNPs (1, 0.1, 0.01 and $0.001 \mathrm{mg} / \mathrm{ml}$ ) for $24 \mathrm{~h}$. Percentages of dying cells were estimated labelling cells with Sytox and Hoechst (Molecular Probes). Automated imaging was performed using the ArrayScan ${ }^{\circledR}$ (ThermoFisher) equipped with a $40 \times$ air objective. More than 300 fields per conditions have been assayed for the statistical evaluation of cell death.

\section{Statistics}

Data are expressed with the mean \pm standard error $( \pm$ S.D.). Normality of dataset was assessed in each experiment by applying either Kolmogorov-Smirnov test (with Dallas-Wilkinson-Lille for P value) or Skewness test. Comparisons were done using: unpaired $t$-test, oneway analysis of variance (ANOVA), followed by Tukey post hoc test. Statistical tests were carried out using PRISM5.01 (GraphPad Software).

\section{Additional files}

Additional file 1: Figure S1. Synthetic route for Cy5.5-AuNPs. General scheme for the synthesis of surface-engineered Cy5.5-AuNPs. PEG-AuNPs are synthesized using sodium citrate as reducing agent and preliminary capping ligand. Purified PEG-AuNPs have been functionalized by forming a stable amide bond between PEG-NH${ }_{2}$ and NHS activated chromophore Cy5.5.

Additional file 2: Figure S2. Cy5.5-AuNPs in tail vein-injected mice. Panels A shows the FLI analysis of mice receiving a single injection of Cy5.5-AuNps in the tail vein that were sacrificed 5 days after the injection. Epifluorescence scale is plotted on the left side of the panel A. A representative confocal scan of the cerebral cortex showing NeuN and Cy5.5 in mice injected with the vehicle and in mice injected with Cy5.5-AuNPs are shown in panels $B$ and $C$, respectively ( $n=3$ for each group). Scale bar $100 \mu \mathrm{m}$.

Additional file 3: Figure S3. Cy5.5-AuNPs in intra parenchymal injected mice. Panel A shows FLI analysis in brains receiving a single intra parenchymal injection of Cy5.5-AuNPs. Epi-fluorescence scale is plotted on the right side of the panel. Arrow in panel A indicates one of these brains that was subsequently sectioned in coronal slabs and further assayed for FLI $\mathrm{FLI}$ analysis (B). Epi fluorescence scale is plotted on the right side of the panel. Panels $C$ and $D$ show confocal scans of the cerebral cortex from a Cy5.5-AuNPs-injected mouse labelled for Iba1, Cy5.5 and Au. Iba $1^{+}$cells were scored in both the contralateral (C) and the ipsilateral cerebral cortex (D). Percentages ( \pm S.D.) of $\mid \mathrm{ba} 1^{+}$cells are shown in the histogram of panel $E(n=3)$. Arrow in panel $D$ indicates a single $\mid \mathrm{ba} 1^{+}$cell that is shown at high magnification in the confocal cross section of panel F. Scale bar $100 \mu \mathrm{m} .{ }^{*} \mathrm{p}<0.05$ unpaired t test.

Additional file 4: Figure S4. Co-localization of Au, Cy5.5 and NeuN in cortical neurons. Coronal sections from mice receiving a single intraparenchymal injection of Cy5.5-AuNPs were labelled for NeuN (C) and submitted to confocal imaging for Au (A) and Cy5.5 (B). To maximize the probability to find triple positive cells we did the imaging in the cortical wall in a region that was adjacent the site of injection. Merge panel in D show co-localization of Cy5.5 and Au in $\mathrm{NeuN}^{+}$cells $(n=3)$. Scale bar $30 \mu \mathrm{m}$.

\section{Abbreviations}

AuNPs: gold nanoparticles; CNS: central nervous system; BBB: blood brain barrier; PEG: polyethylene glycol; CFS: cerebrospinal fluid; ICM: intra cisterna magna; FLl: fluorescence imaging; TEM: transmission electron microscopy; FR: fluorescence ratio; ICP-OES: Inductively Coupled Plasma-Optical Emission Spectrometers; DLS: dynamic light scattering; ROI: region of interest.

\section{Authors' contributions}

AS performed in vivo analysis of Cy5.5-AuNPs, MG performed in situ analysis of AuNPs distribution, LP and DA did the synthesis and the characterization of particles used in this study, GM and PS conceived the study and revised the manuscript, AM and LM are the corresponding authors. They designed the study, revised the manuscript and also provided funding support. All authors read and approved the final manuscript.

\section{Author details}

${ }^{1}$ Experimental Imaging Centre, San Raffaele Scientific Institute, 20132 Milan, Italy. ${ }^{2}$ Neuroimmunology Unit, Division of Neuroscience, Institute of Experimental Neurology (INSPE), San Raffaele Scientific Institute, 20132 Milan, Italy. ${ }^{3}$ Institute of Molecular Science and Technologies (ISTM), CNR, Via C. Golgi 19, 20133 Milan, Italy. ${ }^{4}$ Neuropathology Unit, Division of Neuroscience, Institute of Experimental Neurology (INSPE), San Raffaele Scientific Institute, 20132 Milan, Italy. ${ }^{5}$ Chemistry Department, Università degli Studi di Milano, Via Venezian 21, 20133 Milan, Italy.

\section{Acknowledgements}

LM and GM are supported by an unrestricted grant from BMW, Italy. LP acknowledges MIUR-Italy (contract 2015RNWJAM 002) for financial support. We thank people from the Alembic Facility of the San Raffaele Hospital for their technical help and Marcello Marelli (ISTM-CNR) for AuNPs TEM. We also thank Annamaria Finardi for her technical assistance in mouse handling.

\section{Competing interests}

The authors declare that they have no competing interests.

\section{Availability of data and materials}

Data regarding each experiment are available from corresponding authors on reasonable request.

\section{Consent for publication}

This manuscript is approved by all authors for the submission.

\section{Ethics approval and consent to participate}

The authors state that they obtained the appropriate institutional approval for the use of mice in this study.

\section{Funding}

This work was supported by BMW (Italy, 2018 unrestricted grant) and by MIUR (2015RNWJAM 002).

\section{Publisher's Note}

Springer Nature remains neutral with regard to jurisdictional claims in published maps and institutional affiliations.

Received: 21 September 2018 Accepted: 21 March 2019

Published online: 03 April 2019

\section{References}

1. Cagno V, Andreozzi P, D'Alicarnasso M, Jacob Silva P, Mueller M, Galloux M, Le Goffic R, Jones ST, Vallino M, Hodek J, et al. Broad-spectrum non-toxic antiviral nanoparticles with a virucidal inhibition mechanism. Nat Mater. 2018:17:195-203.

2. Vo-Dinh T, Inman BA. What potential does plasmonics-amplified synergistic immuno photothermal nanotherapy have for treatment of cancer? Nanomed Nanotechnol Biol Med. 2018;13:139-44.

3. Etheridge ML, Campbell SA, Erdman AG, Haynes CL, Wolf SM, McCullough $J$. The big picture on nanomedicine: the state of investigational and 
approved nanomedicine products. Nanomed Nanotechnol Biol Med. 2013:9:1-14.

4. Velasco-Aguirre C, Morales F, Gallardo-Toledo E, Guerrero S, Giralt E, Araya E, Kogan MJ. Peptides and proteins used to enhance gold nanoparticle delivery to the brain: preclinical approaches. Int I Nanomed. 2015;10:4919-36.

5. Pourgholi F, Hajivalili M, Farhad JN, Kafil HS, Yousefi M. Nanoparticles: novel vehicles in treatment of Glioblastoma. Biomed Pharmacother. 2016:77:98-107.

6. Lin Z, Monteiro-Riviere NA, Riviere JE. Pharmacokinetics of metallic nanoparticles. Wiley Interdiscip Rev Nanomed Nanobiotechnol. 2015;7:189-217.

7. Key J, Leary JF. Nanoparticles for multimodal in vivo imaging in nanomedicine. Int J Nanomed. 2014;9:711-26.

8. Haume K, Rosa S, Grellet S, Smialek MA, Butterworth KT, Solov'yov AV, Prise KM, Golding J, Mason NJ. Gold nanoparticles for cancer radiotherapy: a review. Cancer Nanotechnol. 2016;7:8.

9. Larner SF, Wang J, Goodman J, Altman MBO, Xin M, Wang KKW. In vitro neurotoxicity resulting from exposure of cultured neural cells to several types of nanoparticles. J Cell Death. 2017;10:1179670717694523.

10. Paviolo C, Stoddart PR. Gold nanoparticles for modulating neuronal behavior. Nanomaterials. 2017;7(4):92.

11. De Jong WH, Hagens WI, Krystek P, Burger MC, Sips AJ, Geertsma RE. Particle size-dependent organ distribution of gold nanoparticles after intravenous administration. Biomaterials. 2008;29:1912-9.

12. Sonavane G, Tomoda K, Makino K. Biodistribution of colloidal gold nanoparticles after intravenous administration: effect of particle size. Colloids Surf B Biointerfaces. 2008;66:274-80.

13. Betzer O, Shilo M, Opochinsky R, Barnoy E, Motiei M, Okun E, Yadid G, Popovtzer R. The effect of nanoparticle size on the ability to cross the blood-brain barrier: an in vivo study. Nanomedicine. 2017:12:1533-46.

14. Clark AJ, Davis ME. Increased brain uptake of targeted nanoparticles by adding an acid-cleavable linkage between transferrin and the nanoparticle core. Proc Natl Acad Sci USA. 2015;112:12486-91.

15. Lipka J, Semmler-Behnke M, Sperling RA, Wenk A, Takenaka S, Schleh C, Kissel T, Parak WJ, Kreyling WG. Biodistribution of PEG-modified gold nanoparticles following intratracheal instillation and intravenous injection. Biomaterials. 2010:31:6574-81.

16. Papastefanaki F, Jakovcevski I, Poulia N, Djogo N, Schulz F, Martinovic T, Ciric D, Loers G, Vossmeyer T, Weller H, et al. Intraspinal delivery of polyethylene glycol-coated gold nanoparticles promotes functional recovery after spinal cord injury. Mol Ther. 2015:23:993-1002.

17. Shilo M, Motiei M, Hana P, Popovtzer R. Transport of nanoparticles through the blood-brain barrier for imaging and therapeutic applications. Nanoscale. 2014;6:2146-52.

18. Gromnicova R, Kaya M, Romero IA, Williams P, Satchell S, Sharrack B, Male D. Transport of gold nanoparticles by vascular endothelium from different human tissues. PLoS ONE. 2016;11:e0161610.

19. Schaffler M, Sousa F, Wenk A, Sitia L, Hirn S, Schleh C, Haberl N, Violatto M, Canovi M, Andreozzi P, et al. Blood protein coating of gold nanoparticles as potential tool for organ targeting. Biomaterials. 2014;35:3455-66

20. Sousa F, Mandal S, Garrovo C, Astolfo A, Bonifacio A, Latawiec D, Menk RH, Arfelli F, Huewel S, Legname G, et al. Functionalized gold nanoparticles: a detailed in vivo multimodal microscopic brain distribution study. Nanoscale. 2010;2:2826-34.

21. Niewoehner J, Bohrmann B, Collin L, Urich E, Sade H, Maier P, Rueger P, Stracke JO, Lau W, Tissot AC, et al. Increased brain penetration and potency of a therapeutic antibody using a monovalent molecular shuttle. Neuron. 2014:81:49-60.

22. Gromnicova R, Yilmaz CU, Orhan N, Kaya M, Davies H, Williams $P_{4}$ Romero IA, Sharrack B, Male D. Localization and mobility of glucosecoated gold nanoparticles within the brain. Nanomed Nanotechnol Biol Med. 2016:11:617-25

23. Lasagna-Reeves C, Gonzalez-Romero D, Barria MA, Olmedo I, Clos A, Sadagopa Ramanujam VM, Urayama A, Vergara L, Kogan MJ, Soto C. Bioaccumulation and toxicity of gold nanoparticles after repeated administration in mice. Biochem Biophys Res Commun. 2010;393:649-55.
24. Jung S, Bang M, Kim BS, Lee S, Kotov NA, Kim B, Jeon D. Intracellular gold nanoparticles increase neuronal excitability and aggravate seizure activity in the mouse brain. PLOS ONE. 2014:9:e91360.

25. Mufson EJ, Kroin JS, Liu YT, Sobreviela T, Penn RD, Miller JA, Kordower JH. Intrastriatal and intraventricular infusion of brain-derived neurotrophic factor in the cynomologous monkey: distribution, retrograde transport and co-localization with substantia nigra dopamine-containing neurons. Neuroscience. 1996;71:179-91.

26. Wersall P, Ohlsson I, Biberfeld P, Collins VP, von Krusenstjerna S, Larsson $\mathrm{S}$, Mellstedt $\mathrm{H}$, Boethius J. Intratumoral infusion of the monoclonal antibody, mAb 425, against the epidermal-growth-factor receptor in patients with advanced malignant glioma. Cancer Immunol Immunother CII. 1997:44:157-64.

27. Ochs G, Penn RD, York M, Giess R, Beck M, Tonn J, Haigh J, Malta E, Traub $M$, Sendtner M, Toyka KV. A phase I/I trial of recombinant methionyl human brain derived neurotrophic factor administered by intrathecal infusion to patients with amyotrophic lateral sclerosis. Amyotroph Lateral Scler Other Motor Neuron Disord. 2000;1:201-6.

28. Okuda Y, Sakoda S, Fujimura H, Nagata S, Yanagihara T, Bernard CC. Intrathecal administration of neutralizing antibody against Fas ligand suppresses the progression of experimental autoimmune encephalomyelitis. Biochem Biophys Res Commun. 2000;275:164-8.

29. Butti E, Bergami A, Recchia A, Brambilla E, Del Carro U, Amadio S, Cattalini A, Esposito M, Stornaiuolo A, Comi G, et al. IL4 gene delivery to the CNS recruits regulatory $T$ cells and induces clinical recovery in mouse models of multiple sclerosis. Gene Ther. 2008;15:504-15.

30. Furlan R, Poliani PL, Marconi PC, Bergami A, Ruffini F, Adorini L, Glorioso JC, Comi G, Martino G. Central nervous system gene therapy with interleukin-4 inhibits progression of ongoing relapsing-remitting autoimmune encephalomyelitis in Biozzi AB/H mice. Gene Ther. 2001;8:13-9.

31. Papisov MI, Belov VV, Gannon KS. Physiology of the intrathecal bolus: the leptomeningeal route for macromolecule and particle delivery to CNS. Mol Pharm. 2013;10:1522-32.

32. Silvestri A, Zambelli V, Ferretti AM, Salerno D, Bellani G, Polito L. Design of functionalized gold nanoparticle probes for computed tomography imaging. Contrast Media Mol Imaging. 2016;11:405-14.

33. Blanco E, Shen $\mathrm{H}$, Ferrari M. Principles of nanoparticle design for overcoming biological barriers to drug delivery. Nat Biotechnol. 2015;33:941-51.

34. Link S, El-Sayed MA. Optical properties and ultrafast dynamics of metallic nanocrystals. Annu Rev Phys Chem. 2003;54:331-66.

35. de Ceglia R, Chaabane L, Biffi E, Bergamaschi A, Ferrigno G, Amadio S, Del Carro U, Mazzocchi N, Comi G, Bianchi V, et al. Down-sizing of neuronal network activity and density of presynaptic terminals by pathological acidosis are efficiently prevented by diminazene aceturate. Brain Behav Immun. 2015;45:263-76.

36. Biffi E, Menegon A, Piraino F, Pedrocchi A, Fiore GB, Rasponi M. Validation of long-term primary neuronal cultures and network activity through the integration of reversibly bonded microbioreactors and MEA substrates. Biotechnol Bioeng. 2011;109:166-75.

37. Connor EE, Mwamuka J, Gole A, Murphy CJ, Wyatt MD. Gold nanoparticles are taken up by human cells but do not cause acute cytotoxicity. Small. 2005; 1:325-7.

38. He H, Xie C, Ren J. Nonbleaching fluorescence of gold nanoparticles and its applications in cancer cell imaging. Anal Chem. 2008;80:5951-7.

39. Davalos D, Grutzendler J, Yang G, Kim JV, Zuo Y, Jung S, Littman DR, Dustin ML, Gan WB. ATP mediates rapid microglial response to local brain injury in vivo. Nat Neurosci. 2005;8:752-8.

40. Muzio L, Martino G, Furlan R. Multifaceted aspects of inflammation in multiple sclerosis: the role of microglia. J Neuroimmunol. 2007;191:39-44.

41. Cho WS, Cho M, Jeong J, Choi M, Cho HY, Han BS, Kim SH, Kim HO, Lim YT, Chung BH. Acute toxicity and pharmacokinetics of $13 \mathrm{~nm}$-sized PEGcoated gold nanoparticles. Toxicol Appl Pharmacol. 2009;236:16-24.

42. Chen G, Roy I, Yang C, Prasad PN. Nanochemistry and nanomedicine for nanoparticle-based diagnostics and therapy. Chem Rev. 2016;116:2826-85.

43. Raliya R, Saha D, Chadha TS, Raman B, Biswas P. Non-invasive aerosol delivery and transport of gold nanoparticles to the brain. Sci Rep. 2017:7:44718.

44. Siddiqi NJ, Abdelhalim MA, El-Ansary AK, Alhomida AS, Ong WY. Identification of potential biomarkers of gold nanoparticle toxicity in rat brains. J Neuroinflamm. 2012:9:123. 
45. Kreyling WG, Abdelmonem AM, Ali Z, Alves F, Geiser M, Haberl N, Hartmann R, Hirn S, de Aberasturi DJ, Kantner K, et al. In vivo integrity of polymer-coated gold nanoparticles. Nat Nanotechnol. 2015;10:619-23.

46. Louveau A, Smirnov I, Keyes TJ, Eccles JD, Rouhani SJ, Peske JD, Derecki NC, Castle D, Mandell JW, Lee KS, et al. Structural and functional features of central nervous system lymphatic vessels. Nature. 2015;523:337-41.

47. Ballabio A, Gieselmann V. Lysosomal disorders: from storage to cellular damage. Biochem Biophys Acta. 2009;1793:684-96.

48. Furlan R, Poliani PL, Galbiati F, Bergami A, Grimaldi LM, Comi G, Adorini L, Martino G. Central nervous system delivery of interleukin 4 by a nonreplicative herpes simplex type 1 viral vector ameliorates autoimmune demyelination. Hum Gene Ther. 1998;9:2605-17.
49. Muzio L, Cavasinni F, Marinaro C, Bergamaschi A, Bergami A, Porcheri C, Cerri F, Dina G, Quattrini A, Comi G. Cxcl10 enhances blood cells migration in the sub-ventricular zone of mice affected by experimental autoimmune encephalomyelitis. Mol Cell Neurosci. 2010;43:268-80.

50. Arno B, Grassivaro F, Rossi C, Bergamaschi A, Castiglioni V, Furlan R, Greter M, Favaro R, Comi G, Becher B, et al. Neural progenitor cells orchestrate microglia migration and positioning into the developing cortex. Nat Commun. 2014;5:5611.

51. Cerri F, Gavazzi A, Previtali SC, Franceschi M, Lopez ID, Scarlato M, Podini P, Comi G, Quattrini A. Diffuse intraneural leiomyoma in a case of sensorimotor neuropathy. Acta Neuropathol. 2009;117:595-7.
Ready to submit your research? Choose BMC and benefit from:

- fast, convenient online submission

- thorough peer review by experienced researchers in your field

- rapid publication on acceptance

- support for research data, including large and complex data types

- gold Open Access which fosters wider collaboration and increased citations

- maximum visibility for your research: over $100 \mathrm{M}$ website views per year

At BMC, research is always in progress.

Learn more biomedcentral.com/submissions 